\title{
New patterns in wine consumption: the wine by the glass trend
}

\author{
Diletta Acuti, University of Florence \\ Valentina Mazzoli, University of Florence \\ Laura Grazzini, University of Florence \\ Rinaldo Rinaldi, University of Florence
}

\begin{abstract}
Purpose. The purpose of this study is to advance the understanding of wine by the glass (WBG) consumption as a new growing trend in wine consumption. To this end, the roles of risk perception, wine involvement and variety seeking are investigated in determining WBG purchase intentions.

Design/methodology/approach. Two studies based on a scenario-based survey have been conducted. In Study $1(\mathrm{n}=248)$, the relationship between WBG risk perception and WBG purchase intention mediated by variety seeking is tested. In Study $2(n=200)$, the relationship between wine involvement and WBG purchase intention with the mediating role of variety seeking is analysed.

Findings. Results show that variety seeking plays a key role in determining WBG purchase intentions considering both WBG perceived risk and wine involvement as independent variables.

Research limitations/implications. The study advances the literature on WBG consumption by enclosing the psychological mechanism (i.e., variety seeking) behind consumers' WBG purchase intentions. The main limitation of this study lies in it being conducted in a single country (i.e., Italy). Practical implications. This paper provides useful guidelines for wine managers. Specifically, variety seeking can attract consumers in new wine consuming places based on a rich assortment. Moreover, it can present a challenge to wine producers in creating brand loyalty.

Originality/value. Although WBG is a growing trend in wine consumption, empirical studies are still scant and a deeper comprehension of its antecedents and consequences is needed. By showing variety seeking as the mechanism behind WBG consumption, this study offers a new theoretical explanation of this phenomenon.
\end{abstract}

Keywords: wine by the glass (WBG), variety seeking, wine consumption, risk perception, wine involvement 


\section{Introduction}

Wine consumption trends have changed over the years. The first recorded archaeological evidence of the presence of vitis vinifera was found at some sites in China (about 7000 years BC) and the oldest evidence of wine production was found in Armenia (around 4100 BC). However, it is only in Ancient Greece that wine consumption evolved as we conceive it today. As with the food industry, many factors have influenced the evolution of wine consumption over time, such as demographic growth, historical events, plagues, the balance of supply and demand, internationalization of production and consumption (Tiu Wright et al., 2001; Capasso et al., 2015).

Nowadays, wine consumption is continuing to evolve because of different current circumstances. Thus, wine is an integral component of the culture of many countries, a form of entertainment in others, and an informed choice for advocates of its health benefits (Bisson et al., 2002). New countries have started to produce wine - such as Australia, Chile and the USA - competing with the classic wine producers and creating new competitive scenarios (Campbell and Guibert, 2006; Montaigne and Coelho, 2012). Globalization has facilitated international exchange of wine and has enabled consumers to choose among different typologies of wine (Anderson and Pinilla, 2018). This variety of wine has pushed wine consumers to become more aware of wine characteristics, more exigent and more curious. The advent of the Internet and social media has provided consumers with new instruments to find any kind of information about wine, increasing wine knowledge and expertise (Galati et al., 2017; Pucci et al., 2019). The rapid worldwide access to information has resulted in a more knowledgeable and empowered consumer with a more sophisticated understanding of product value and a discriminating demand for quality (Dodd et al., 2005).

Consumers' willingness to explore wine characteristics and taste different wines is confirmed by the increasing demand for local wine courses and training experiences in many countries (Charters and Ali-Knight, 2000; Carlsen and Boksberger, 2015). This trend also implies a change in where and how wine is consumed. The expansion of wine culture is changing consumers' behaviour, with the consumption of wine outside the household increasing too (Bernetti et al., 2006). Wine is no longer sold only in supermarkets or restaurants, as there are many wine bars, pubs and wineries that offer consumers a place where they can taste different wines. Moreover, wine tourism offers many experiences such as visits to vineyards, wine festivals and wine shows (Maizza and Rosato, 2008; Thanh and Kirova, 2018).

Consumers can choose between buying a bottle or a single glass of wine. Wine by the glass (WBG) gives consumers the opportunity to taste more wines with the same meal and, in addition, is compatible with a more moderate and healthier consumption (Giacomarra et al., 2016; Samoggia, 2016). Moreover, the possibility of consuming WBG allows consumers to ask for the wine they prefer 
without being forced to buy the same - shared - bottle. Another consequence of WBG consumption is the limiting of wine waste, contributing to a more ethical consumption, in line with new consumers' requirements (D’Amico et al., 2016; Bruwer and Campusano, 2018). This new consumption trend requires companies to satisfy the need of increasingly demanding consumers and to offer a tasting experience through innovative systems. For instance, companies would need to be equipped with a dispenser that guarantees the protection and conservation of the wine, thereby preventing normal wine alterations. For this reason, it is important for managers to understand the dynamic of wine consumption today.

Based on these premises, this research investigates the role of variety seeking in leading consumers to buy WBG. We interpret variety seeking as a "variety drive" (Faison, 1977), referring to the assumption that a switch to something different or new increases the stimulation when purchasing (Menon and Kahn, 1995). Specifically, this research proposes that variety seeking is the underlying mechanism that explains how wine involvement and risk perception influence consumers' WBG purchase intentions. So, even if a consumer is completely satisfied with the purchased product - in this case, a specific wine - she/he will occasionally purchase something different to their regular choice (Meixner and Knoll, 2012). Methodologically, this research presents two different studies that test the hypotheses proposed through a survey.

This research makes several theoretical contributions. First, it advances knowledge about the current wine consumption trend (i.e., WBG), which has been addressed previously by just two academic studies (Bruwer et al., 2017; Bruwer and Cohen, 2019). Second, the study shows the mediating role of variety seeking in WBG consumption, thereby offering a new theoretical explanation of this phenomenon. From a managerial perspective, in revealing the role of variety seeking, this paper provides useful information to better define marketing strategies that should support and foster this new trend. On the one hand, variety seeking can attract consumers to new wine consuming places based on the rich assortment available. On the other hand, variety seeking can present a challenge to wine producers in terms of creating brand loyalty.

\section{Literature Review}

\section{Wine consumption}

In the early 2000s, global wine consumption increased significantly and reached a peak in 20072008. Since 2009, however, wine consumption has been relatively stable. In 2018, the world's wine consumption was still stable and at 246 million hectolitres, it represented eight per cent of the total recorded alcohol consumed worldwide, after spirits and beer (World Health Organization, 2014). The five biggest consumers, namely the USA, France, Italy, Germany and China, together represent half 
of the world's consumption (Forbes, 2019). Overall European wine consumption has decreased in recent years, in favour of high-quality wine and a reduction in the consumption of so-called "table wine" (Samoggia, 2016). Moreover, in last years, consumers are increasingly considering environmental impacts when making purchases, thus expressing their desire for sustainable wines (Bresciani et al., 2016; Galati et al., 2019).

Nowadays, wine is seen as a companion to a high-quality diet and fine cuisine, at home as well as in pubs, wine bars and restaurants. Wine is widely served as a food accompaniment in restaurants (Bruwer et al., 2017), and wine sales can increase a restaurant's profitability significantly (Barth, 2011; Berenguer et al., 2009; Frost, 2015; Gil et al., 2009; Hansen, 2015). For instance, in Spain, which is the biggest wine exporter (Forbes, 2019), wine consumption accounts for 32 per cent of the average restaurant bill, while in Australia, which is the fifth biggest exporter (Forbes, 2019), profitability coming from wine sales varies between 26 per cent and 29 per cent (Bruwer et al., 2012; Gil et al., 2009). However, studies have shown that selecting wine in a dining experience is often associated with a stressful experience and has an associated risk perception (Bruwer et al., 2017; Lacey et al., 2009). Moreover, the great variety of wines available on the market contributes to the complexity of wine choice (Lockshin et al., 2006). Indeed, wine is in itself a complex product that scholars define as an experience good, since its quality cannot be assessed before its consumption (Charters and Pettigrew, 2007; Barber et al., 2007). Thus, wine quality needs to be deduced before consumption using several tangible and intangible variables. The main difficulty lies in the huge number of attributes associated with wine (Escobar et al., 2018). Among others, brand names provide consumers with several product cues, including quality (D'Alessandro and Pecotich, 2013). Similarly, the region of origin and grape variety play a key role in the consumers' decision-making process as indicators of the quality of the wine (Gluckman, 1990). Price is a very important attribute that affects wine choice (Galati et al., 2018). Indeed, this cue can be used as a proxy of product quality, especially when there are a small number of other cues available, when the product cannot be evaluated before being purchased, and when there is some degree of risk of making a wrong choice (Mitchell and Greatorex, 1989).

\section{Wine by the glass consumption as a new trend in wine consumption}

As wine choice is often perceived by consumers as complex and risky, the single-serve wine by the glass (WBG) strategy offers a great business opportunity for restaurants, pubs and wine bars to reduce consumers' risk perception. Indeed, as Jaeger et al. (2010) demonstrated, the availability of WBG can decrease risk perception and in turn increase wine consumption (Terrier and Jaquinet, 2016). Consequently, the opportunity to order WBG is a good option for both customers (they can drink 
wine without paying for a bottle) and restaurateurs (the gross profit for the restaurant is greater for WBG than for a bottle of the same wine). WBG is cheaper for the customer, thereby minimizing the financial risk (Jaeger et al., 2010), and could be considered a risk reduction strategy (Schiffman et $a l ., 2011)$. In this case, the risk reduction strategy used could allow the customer to obtain more information about their choice of wine by directly tasting the product (Schiffman et al., 2011; Wansink et al., 2006).

Beyond risk reduction, as Yoon and Stacy (2015) highlighted, the single-serve experience is a powerful intersection of business (higher margins, incremental sales) and increased consumer benefits (more customization, more choices). Indeed, more WBG options usually result in restaurants selling expensive wines faster (Frost, 2015), while an increasing number of wines on the wine list has a positive effect on the perception of quality of a restaurant, a pub or a wine bar (Barth, 2011; Berenguer et al., 2009). Moreover, increased WBG options may help attract a larger and more diverse customer base, which can ultimately enhance the amount of sales revenue for the business activity (Jacob and Neal, 2011).

Despite these advantages, the WBG strategy has so far been largely underutilized (Frost, 2015; Hansen, 2015; Yoon and Stacy, 2015) and studies investigating this phenomenon are still scant (i.e., Bruwer and Cohen, 2019; Bruwer et al., 2017). So, as WBG consumption is expected to grow (Yoon and Stacy, 2015) a deeper comprehension of this phenomenon is needed.

\section{Conceptual Framework and Hypotheses Development}

\section{The influence of risk perception on WBG purchase intentions}

The concept of perceived risk was introduced for the very first time by Bauer (1960). Since its introduction, many studies have investigated the effect of perceived risk on consumer behaviour and consequent marketing decisions. The first conceptualizations of perceived risk considered two main dimensions: on the one hand, the uncertainty of making the wrong choice, and on the other, the consequences of the wrong choice. Modern conceptualizations of perceived risk are multidimensional (Bruwer et al., 2017) and include several categories of risk, namely functional, physical, financial, social, psychological and time risk (Schiffman et al., 2011).

Risk perception usually leads consumers to think about the negative consequences of an action, so consumers attempt to cope with uncertainty using various risk reduction strategies (Johnson and Bruwer, 2004). From a consumer's point of view, risk reduction strategies can be defined as those actions taken to decrease overall novelty (Shepherd et al., 2000). 
As wine is often perceived as a complex product whose quality cannot be assessed until its actual consumption, perceived risk represents one of the main factors that affect decision-making in wine purchasing situations (Bruwer et al., 2013).

However, by trying a small sample of wine, the level of perceived risk usually reduces. Accordingly, some studies have considered WBG to be a risk reduction strategy (i.e., Lacey et al., 2009; Bruwer and Cohen, 2019). In particular, WBG reduces the functional risk embedded in wine consumption. Consequently, as the value of the wine increases, tasting the wine becomes more important in the decision-making process (Johnson and Bruwer, 2004). Thus, the WBG strategy allows marketers to push more expensive wine sales by reducing functional risk.

Previous works have operationalized WBG perceived risk using an 18-item scale to measure all risk dimensions in relation to WBG consumption (Bruwer et al., 2017; Bruwer and Cohen, 2019). This scale considers WBG as a consumer's risk reduction strategy and implies that the higher the WBG perceived risk is, the higher the WBG purchase intentions are. Based on this, we hypothesize that perceived risk positively affects consumers' WBG purchase intentions, because WBG is perceived as a risk reduction strategy. Formally;

\section{H1: Perceived risk reduction positively affects WBG purchase intention}

\section{The influence of wine involvement on WBG purchase intentions}

Involvement is defined as “a person's perceived relevance of the object based on inherent values, needs and interests" (Zaichkowsky, 1985, p. 342). The relevance of involvement in the marketing literature can be associated with its significant influence on consumer purchasing behaviour (Dholakia, 2001). Product involvement represents one of the most addressed involvement types in both the conceptual and empirical literatures (Hollebeek et al., 2007). Product involvement levels have been shown to influence consumer attitudes, brand preferences and perceptions (e.g., Brisoux and Cheron, 1990; Celsi and Olson, 1988; Lockshin et al., 2006; O’Cass, 2000).

In the wine sector, wine involvement has been conceptualized as "the interest, enthusiasm and excitement that consumers exhibit towards wine" (Hollebeek et al., 2007, p. 1036). Research has identified involvement as an important variable that has a certain impact upon consumer behaviour in the wine market (Lesschaeve and Bruwer, 2010). Thus, the relevance of involvement in wine purchasing is supported by several studies (e.g., Barber et al., 2007; Bruwer and Buller, 2013; Ogbeide and Bruwer, 2013). Involvement has also been linked to wine buying and it has been shown that consumers with different levels of involvement behave differently (e.g., Bruwer and Huang, 2012; Hirche and Bruwer, 2014). Wine involvement has been consistently linked to wine purchase 
behaviour, with highly and minimally involved consumers exhibiting different behaviours (Lockshin et al., 1997). Consumers' use of key wine attributes such as region of origin and price has been shown to be influenced by consumers' product involvement levels (Zaichkowsky, 1985). In summary, previous research has highlighted that highly involved consumers tend to utilize more product cues in their purchase decisions and are interested in learning more about wine, while minimally involved consumers tend to simplify their choice decisions by relying on price-based cues more heavily (Hollebeek et al., 2007).

Wine involvement induces a motivational state that influences a person to actively search for productrelated information and give advice about the product class (Dholakia, 2001). Both seeking and providing information about the product category are important behavioural responses to product involvement (Bruwer and Cohen, 2019). Accordingly, WBG consumption represents an active behaviour that the consumer may activate to collect new information about a product.

Based on the above, we hypothesize that consumers that perceive greater levels of wine involvement show greater levels of WBG purchase intentions to satisfy their enthusiasm, and collect novel information, about wine. Formally,

\section{H2: Wine involvement positively affects $W B G$ purchase intentions}

\section{The mediating role of variety seeking}

While literature on WBG risk perception and wine involvement has provided important findings in determining WBG purchase intentions, a clear explanation of the psychological mechanisms that occur in the relationship between these variables is still lacking (Bruwer et al., 2017).

To this end, a relevant construct is provided by variety seeking. Variety seeking has been a topic of interest in wine business research for the past two decades (Olsen et al., 2015). Psychological literature identifies variety seeking as an exploratory behaviour that embeds novelty, unexpectedness, change and complexity that increase people's satisfaction (Berlyne et al., 1963). Hirschman (1980) defined variety seeking as an internal drive or motivating force that motivates the individual to seek out novel information. Accordingly, individuals often change their purchase habits in regard to previously sampled brands because of their satiation with product attributes (McAlister and Pessemier, 1982).

The concept of variety seeking has become of special interest to marketers of products in which there are a large number of choices for consumers, such as wine. In particular, several studies have focused on variety seeking as an important threat to brand loyalty (e.g., Yim and Kannan, 1999). However, variety seeking is also important to maximize brand performance (Olsen et al., 2015). Knox (1998) 
was one of the first to affirm that wine consumption usually involves variety-seeking behaviours. Several studies have investigated the relationship between variety seeking and other aspects of wine purchase behaviour such as age, gender, income and education. However, the current results are contradictory. For instance, while Dodd et al. (1996) found no association between variety seeking and age, income or education, Bruwer and Li (2007) identified a significant relationship between variety seeking and age. Bruwer and Li (2007) found that variety avoiders spent less money on wine annually and consumed wine less frequently than variety-neutral or variety-seeking consumers. Knox (1998) found that variety seekers would buy their preferred wine only once in 15 times since variety seekers are high-spending customers that want a large variety of wine from which to choose. Moreover, it has been shown that consumers often buy wine at a variety of price points, and most consumers show variety-seeking tendencies when it comes to the price paid per bottle of wine (Hussain et al., 2007), leading to erosion of brand loyalty (Papatla and Krishnamurthi, 1996). Despite the linkage between variety-seeking behaviour and price promotions, variety-seeking behaviour is often limited by risk perception. Indeed, as Campbell and Goodstein (2001) pointed out, when a purchase is felt to be of high risk, individuals have a greater preference for familiar options, thereby limiting variety-seeking behaviour. Similarly, Orth and Bourrain (2005) found that consumers are often hesitant to try new brands and varieties because such choices are perceived to be risky. So, variety-seeking behaviours are often associated with the consumer's perception of risk. Thus, WBG purchase intentions might increase when WBG is perceived as a proper risk reduction strategy in wine consumption and variety seeking is activated. We hypothesize consistently that the positive effect of WBG perceived risk on WBG purchase intentions is explained by variety seeking. Formally:

\section{H3: Variety seeking mediates the effect of risk perception on WBG purchase intentions.}

Variety seeking is also often associated with a person's level of involvement with wine. According to Bloch (1986), product involvement is shown by consumers' enduring enthusiasm for certain products. So, wine involvement usually leads consumers to increase their ability to make an appropriate wine selection (Palma et al., 2014; Fernandes Ferreira Madureira and Simões de Sousa Nunes, 2013). Dodd et al. (1996) found that consumers showing greater levels of wine involvement switch the region of their wine purchases frequently.

Wine is often perceived as a complex product (Olsen et al., 2015). Many consumers often appear confused when selecting wine (Hussain et al., 2007). Consequently, in many situations, wine consumers simply purchase a familiar brand to avoid processing the complex information associated with wine purchases. Variety seekers are usually more willing to consult more information sources 
than consumers who seek less variety, perhaps reducing their levels of confusion and making the selection of an unknown wine feel less risky (Dodd et al., 1996). So, WBG purchase intentions may increase as the WBG option simplifies the wine selection process. Specifically, we hypothesize that the positive effect of wine involvement on WBG purchase intentions is explained by variety seeking. Formally:

H4: Variety seeking mediates the effect of wine involvement on WBG purchase intentions.

Our conceptual model is presented in figure 1.

Figure 1: Conceptual Model.

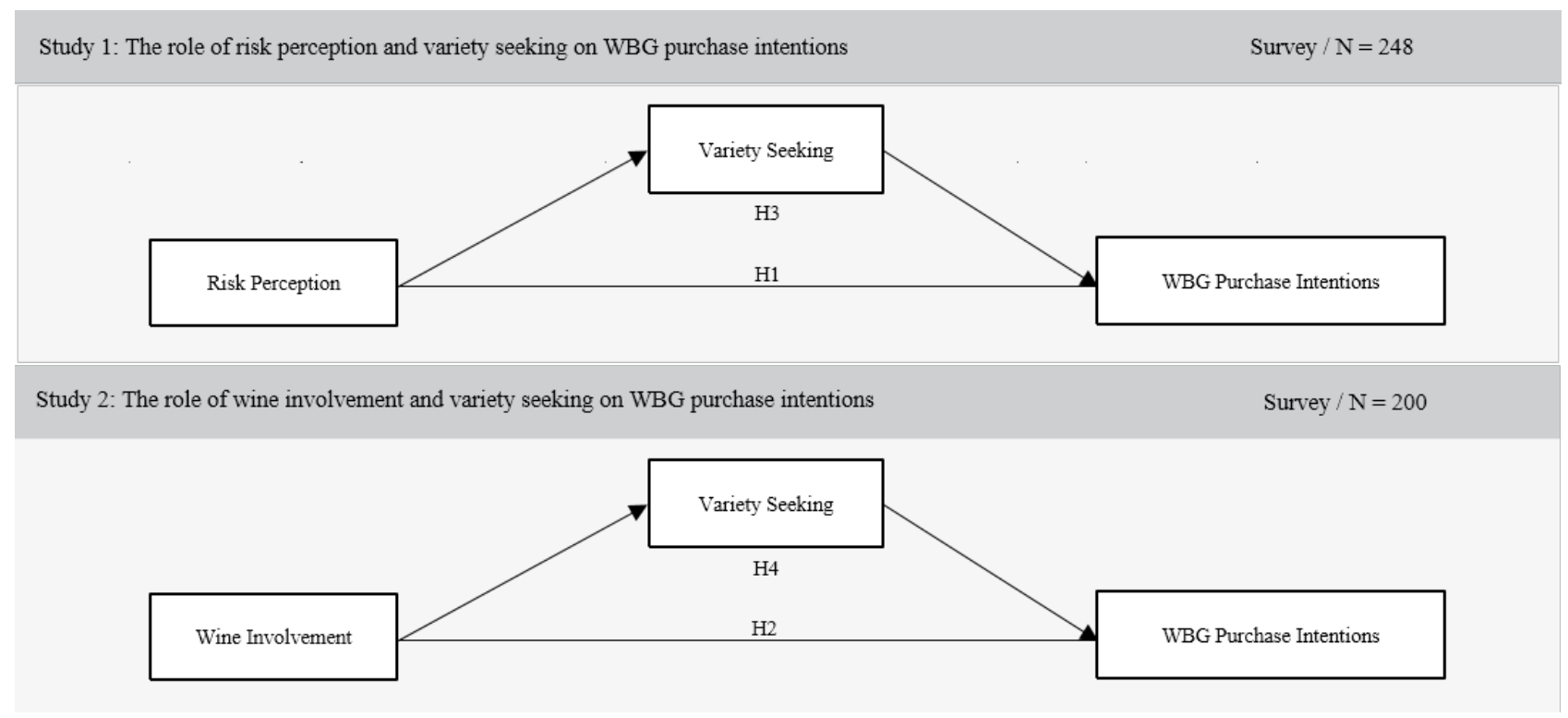

\section{Methodology}

Methodologically the paper presents two scenario-based surveys. Specifically, Study 1 has been design to test the effect of risk perception on consumers' WBG purchase intentions (H1). Drawing from the variety-seeking model (McAlister and Pessemier, 1982), it further assesses the role of variety seeking as the underlining mechanism of the relationship between risk perception and consumers' WBG purchase intentions (H3). Study 2, instead, tests for the effect of wine involvement on consumers' WBG purchase intentions $(\mathrm{H} 2)$, by looking at the mediating role of variety seeking behind this effect (H4).

Study 1 
Study 1 adopts an online survey on an Italian sample. A total of 248 respondents took part in this study. We recruited the participants from the members of Italian social media groups (i.e., Facebook) devoted to wine consumption, such as "Amici del vino" ("Wine friends"), "Vino, arte \& cultura" ("Wine, art \& culture") and "Non solo vino" ("Not wine only"). These groups have more the 1.500 participants and are aimed at sharing contents about wine (e.g., wine labels, wine brands, wine bottles, news about wine, wineries and all that is part of the wine culture in general). We sent the questionnaire to the participants of these groups by a private message. According to Geuens and De Pelsmacker (2017), this choice allowed a more homogeneous group of respondents to be assembled (i.e., wine consumers). In this regard, choosing an Italian sample of wine consumers is highly pertinent for several reasons. For instance, Italy has been the world's foremost wine producer and the wine culture is deeply rooted in this country (Rossi et al., 2014; Bresciani et al., 2016). The questionnaire was written in English, translated into Italian and then back-translated into English. The back-translation method was conducted in order to ensure that the Italian version of the questionnaire had the same content as the English version (Sekaran, 1983). Respondents were asked to imagine being at a wine bar for drinking wine. After that, they were asked to answer questions on risk perception, variety seeking and purchase intentions. The key variables of interest were measured using previously validated scales. Participants provided ratings of risk perception $(\alpha=.91)$ by using a 18-item scale developed by Bruwer et al. (2017). This scale considers WBG to be a consumer's risk reduction strategy and implies that the higher the WBG perceived risk is, the higher the WBG purchase intentions are. Variety seeking $(\alpha=.94)$ has been measured by using the eight-item scale provided by Olsen et al. (2015). Afterwards, participants provided ratings of WBG purchase intentions by adapting Sweeney and Soutar's (2001) item: "My willingness to purchase wine by the glass is...". Participants indicated the degree of their agreement with these items by using a seven-point Likert scale. Finally, demographic data were collected.

\section{Study 2}

A sample of 200 Italian participants was recruited for Study 2. Using the same procedure as in Study 1, we recruited the participants on social media groups devoted to wine consumption (i.e., Amici del vino, Vino, arte \& cultura and Non solo vino). We sent the questionnaire to participants through a private message, checking for those who have already participated in Study 1. These participants have been excluded for participating in Study 2. Same scenario as in Study 1 has been adopted. Respondents were asked to imagine being at a wine bar for drinking wine. After that, they were asked to answer questions on wine involvement, variety seeking and purchase intentions. As with Study 1, the key variables of interest (i.e., wine involvement and variety seeking) were measured using 
previously validated scales. Participants provided ratings of wine involvement $(\alpha=.88)$ by using a tenitem measure developed by Hirche and Bruwer (2014). As with Study 1, variety seeking was measured by using the eight-item scale by Olsen et al. (2015), while WBG purchase intentions were measured by using the Sweeney and Soutar (2001) scale. Participants indicated the degree of their agreement with these items by using a seven-point Likert scale. Finally, demographic data were collected.

\section{Results}

Study 1

Among the 248 participants that took part in Study 1, 53.6\% were females; 34.3\% of the sample were between the ages of 18 and 29,26.6\% were aged 30 to $41,27.8 \%$ were aged between 42 and 54 , and $11.3 \%$ were between the ages of 55 and 70 .

Study 1 tested for the effect of perceived risk and the mediating role of variety seeking on consumers' WBG purchase intentions. According to $\mathrm{H} 1$, we expected that perceived risk reduction positively affected consumers' WBG purchase intentions. Based on $\mathrm{H} 3$, we also predicted that consumers will ascribe greater variety seeking when risk perception is high than in the case of a low level of risk perception, which in turn will affect consumers' WBG purchase intentions.

To test H1, we first calculated a simple linear regression to predict the positive effect of perceived risk on consumers' WBG purchase intentions. A significant regression equation was found $(\mathrm{F}(1,246)$ $=58.118, \mathrm{~b}=.47$, CI 95\% [0.35, 0.59], $p<0.001)$ with an $R^{2}$ of .20. Results thus confirm our H1. In order to test whether differences in risk perception are related to a diverse level of variety seeking (H3), the authors tested a mediation model using PROCESS macro (model 4 bootstrap 5,000; Hayes, 2017), with risk perception as the independent variable and variety seeking as the mediator. As can be seen graphically in Figure 2, results show that a high level of risk perception has a significant effect on variety seeking ( $b=.37$, confidence interval (CI) $95 \%[0.23,0.52]$ ), which in turn has a significant effect on WBG purchase intentions $(b=.55$, CI 95\% [0.47, 0.64]). The high level of risk perception is still a predictor of purchase intentions after controlling for the mediator $(b=.30, \mathrm{CI} 95 \%$ $[0.19,0.40])$, which indicates a partially mediated model. Results reveal that the higher the variety seeking of consumers, the more likely they are to purchase WBG, thereby supporting H3. So, according with the results, we can affirm that variety seeking mediates the effect of risk perception on WBG purchase intentions. 


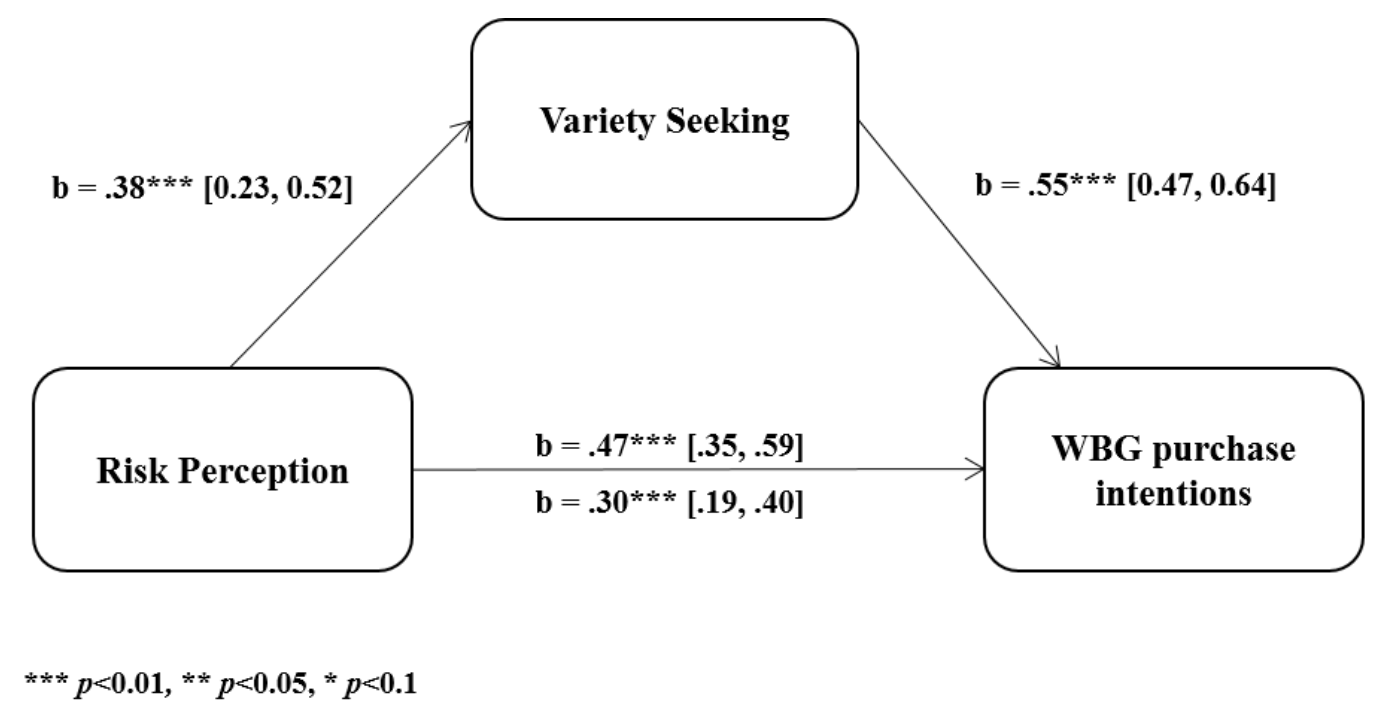

\section{Study 2}

Among the participants who took part in Study 2, 52\% were female; $40.5 \%$ of the sample were between the ages of 18 and 29,24.0\% were aged 30 to 41,24.0\% were aged between 42 and 54, and $11.5 \%$ were aged 55 to 70 .

As with Study 1, Study 2 tested for the effect of wine involvement and for the mediating role of variety seeking on consumers' WBG purchase intentions. According to H2, we hypothesized that wine involvement positively affects consumers' WBG purchase intentions. We also predicted that consumers will ascribe greater variety seeking in the case of a high level of wine involvement than in the case of low level, which in turn will affect consumers' WBG purchase intentions (H4).

To support our H2, a simple linear regression was run with wine involvement as the independent variable and WBG purchase intentions as the dependent variable. A significant regression equation was found $(\mathrm{F}(1,198)=73.083, \mathrm{~b}=.37$, CI 95\% [0.28, 0.45], $p<0.001)$ with an $R^{2}$ of .27 . Results thus confirm our $\mathrm{H} 2$.

To test our H4, a mediation model was tested (model 4 bootstrap 5,000; Hayes, 2017), with wine involvement as the independent variable and variety seeking as the mediator. As can be seen graphically in Figure 3, results show that a high level of wine involvement has a significant effect on variety seeking $(b=.39$, confidence interval $(C I) 95 \%[0.31,0.47])$, which in turn has a significant effect on consumers' WBG purchase intentions $(b=.58$, CI 95\% [0.48, 0.69]). Wine involvement is no longer a significant predictor of consumers' purchase intentions after controlling for the mediator $(b=.02$, CI 95\% $[-0.04,0.10])$, which indicates a fully mediated model. The results thus support H4. 


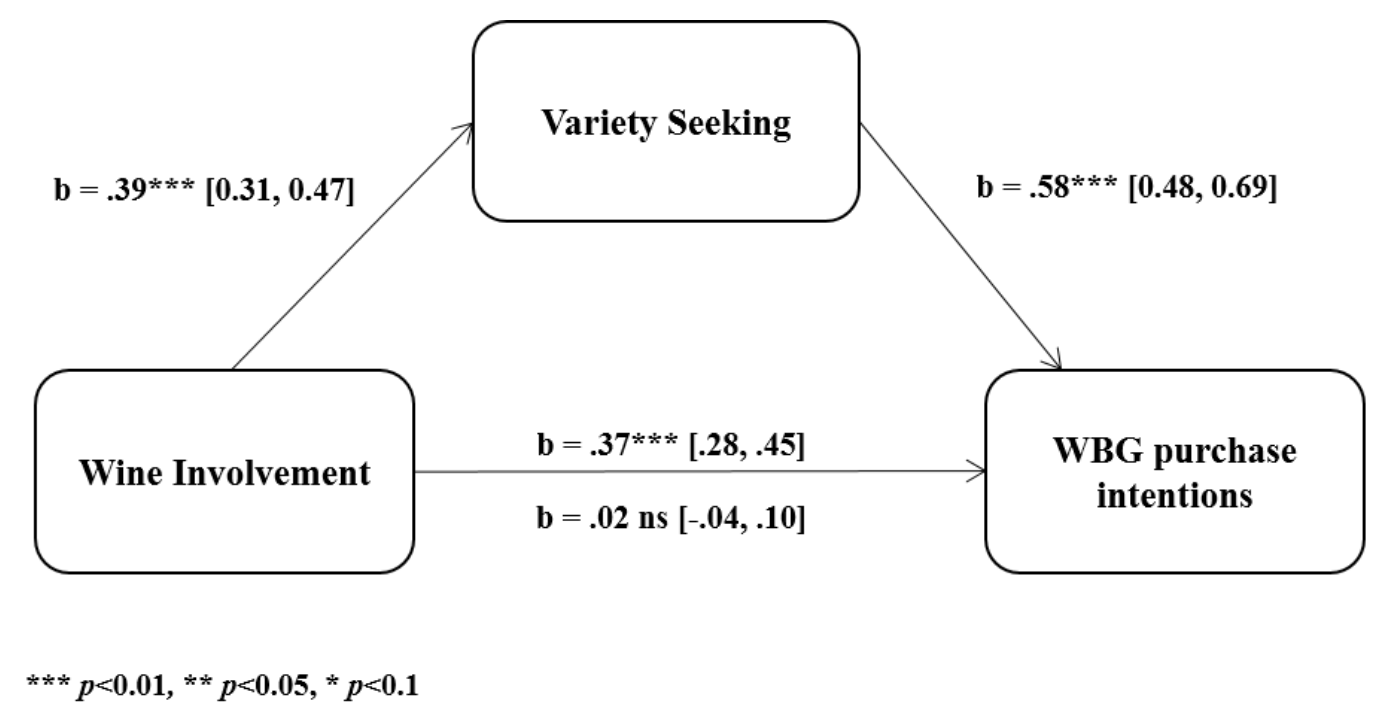

\section{Conclusions}

The aim of the present research is to expand the debate on new consumption trends in the wine industry as the WBG phenomenon. Although the literature on wine consumption is attracting many scholars from different disciplines (Lockshin and Corsi, 2012; Schäufele and Hamm, 2017), the WBG phenomenon remains unexplored (Jaeger et al., 2010). From a consumer point of view, WBG gives the opportunity to taste different wines with the same meal and, in addition, is compatible with a more moderate and healthier consumption (Giacomarra et al., 2016; Samoggia, 2016). From a company point of view, instead, the single-serve WBG strategy offers a great business opportunity for restaurants, pubs and wine bars to reduce consumers' risk perception, thus increasing wine consumption.

Across two studies we investigate the WBG phenomenon, by showing the effect of risk perception and wine involvement on WBG purchase intentions. Drawing from the variety-seeking model (McAlister and Pessemier, 1982), we further enclose the mechanism (i.e., variety seeking) behind the relationship between risk perception, wine involvement and WBG purchase intentions. Specifically, Study 1 tests - and finds evidence for- the positive effect of risk perception on consumers' WBG purchase intentions. It further assesses the mediating role of variety seeking in the relationship between risk perception and WBG purchase intentions. Study 2 instead provides evidence for the positive effect of wine involvement in increasing consumers' WBG purchase intentions, which is in turn mediated by variety seeking. 
The current research has important theoretical and practical implications. First, we advance knowledge on the WBG literature. Despite the relevance of this new approach to consumption, literature has paid scant attention to this new trend (Bruwer et al., 2017). We fill this gap by investigating the role of risk perception and wine involvement on WBG purchase intentions. Our research confirms that that WBG reduces the functional risk embedded in wine consumption (Lacey et al., 2009; Bruwer and Cohen, 2019). In addition, we also show the importance of involvement in WBG purchasing behaviours (Bruwer and Buller, 2013; Ogbeide and Bruwer, 2013).

Second, this research answers the call made by Bruwer and Cohen (2019) to investigate possible psychological mechanisms that could lead to the WBG phenomenon. In this regard, the paper helps in enabling an understanding of why drinking wine by the glass is an increasingly widespread practice, by showing variety seeking as the key mechanism. Although literature recognizes that wine purchasing typically involves variety-seeking behaviours, its effects on wine by the glass consumption have not been addressed. The same is true for wine involvement and risk perception constructs. There is strong evidence that a person's level of involvement with wine and the perceived risk of wine purchasing are related to variety seeking (Olsen et al., 2015), but any further impact on wine consumption remains uncovered. To our knowledge, this is the first research that tests and finds evidence for the mediating role of variety seeking in the relationship between risk perception, wine involvement and WBG purchase intentions.

This research also presents clear managerial implications. Single-serve WBG is increasingly popular among consumers and represent a significant new category in the overall wine market (Unione Italiana Vini, 2019). According to a recent study by Mintel (2019), one of the four trends that will continue in 2019 is growth in food and beverage products in single-serve portions. The way wine is currently consumed has changed completely: customers prefer quality over quantity, they want to be able to match wine with food and try to discover new tastes and new terroirs. In explaining the mechanism behind WBG consumption, this research thus provides useful guidelines for developing proper marketing strategies. Firstly, wine involvement motivates consumers to try various typologies of wine, encouraging them to buy WBG. Certainly, recent trends in wine consumption, such as the improvement in consumers' expertise and the growth of the wine culture, make consumers more curious and variety seeking, thereby encouraging them to taste different wines. The availability of WBG helps to satisfy this need. In the same vein, managers of restaurants, wine bars and other wineselling places should consider WBG as an option capable of increasing consumers' learning about, and interest in, wine. For instance, many wineries organize wine tasting experiences, which enable consumers to taste various wine by glass, and, in the meanwhile, visit new places and learn about the wine production. 
Secondly, WBG consumption can be perceived as a risk reduction strategy, thereby encouraging consumers to vary their wine choices. Accordingly, enhancing WBG benefits should be included in managers' strategies. Thirdly, the diffusion of WBG consumption can attract consumers to new wineconsuming places based on a rich assortment, allowing managers of wine-serving places to make the most of this new opportunity. Fourthly, consumers' variety seeking can present a challenge to wine producers in terms of creating brand loyalty: the offer of different wines is growing, as well as consumers' willingness to taste new wines. Wine producers should therefore be able to attract new tasters and retain their customers. In this vein, they could promote the variety of the wines produced, communicating the different features that characterize their production and thus satisfying consumers' variety seeking with their offer. Finally, consumers' willingness to taste different wines paired with different cuisines allows food service managers to enhance the wine and food experience, thus adding value to their offer. All over the world, there are thousands of wines as well as different kind of cuisines available. This variety allows those consumers with a discerning palate to find the best match between wine and food. It follows that managers should encourage consumers to approach to new tastes and educate them to the right pairing expertise.

This study is not without limitations and may provide inspiration for future research. First, this research, shedding light on new trends in the wine industry, provides an overview of factors that influence wine consumption - such as the internationalization and globalization of production and consumption, the creation of new competitive scenarios, and the enhancement of consumer's expertise and curiosity. However, these factors have not been tested empirically. Second, although the research introduces benefits of WBG both for consumers and companies, it does not prove whether consumers and companies consider these benefits in their consuming and producing choices. In this regard, due to the growing increase of sustainable wine productions (Bresciani et al., 2016; Galati et al., 2019), future research could investigate if WBG consumption can be considered a good strategy to lower wine waste. In the same vein, future research should deeper analyse how companies can effectively communicate the sustainable aspects of WBG consumption to the consumers. Further research could also include market actors' considerations, by investigating for instance the benefits for wine companies in providing WBG service and if this strategy is more efficient in fostering companies growth. Another limitation lies in investigating only consumers' purchase intentions. It follows that a field study or other form of triangulation (e.g., archive data and focus groups) could be worth pursuing to provide a deeper analysis of the phenomenon. Finally, the study was conducted in Italy, which represents a clear case of a country where the wine culture is deeply rooted. Although the diffusion of wine culture is a global phenomenon, further researches could compare wine consumption behaviours in different countries that present different levels of wine culture. 


\section{References}

Anderson, K. and Pinilla, V. (Eds.), (2018), Wine Globalization: A New Comparative History. Cambridge University Press.

Barber, N., Ismail, J. and Dodd, T. (2007), "Purchase attributes of wine consumers with low involvement", Journal of Food Products Marketing, Vol. 14 No, 1, pp. 69-86.

Barth, J.J. (2011), “A model for wine list and wine inventory yield management”, International Journal of Hospitality Management, Vol. 30 No. 3, pp. 701-707.

Bauer, R.A. (1960), “Consumer behavior as risk taking”, in Hancock, R.H. (Ed.), Dynamic Marketing for a Changing World, American Marketing Association, Chicago, IL, pp. 389-398.

Berenguer, G., Gil, I. and Ruiz, M.E. (2009), "Do upscale restaurant owners use wine lists as a differentiation strategy?", International Journal of Hospitality Management, Vol. 28 No. 1, pp. 8695.

Berlyne, D.E., Craw, M.A., Salapatek, P.H. and Lewis, J.L. (1963), "Novelty, complexity, incongruity, extrinsic motivation, and the GSR", Journal of Experimental Psychology, Vol. 66 No. 6, p. 560.

Bernetti, I., Casini, L. and Marinelli, N. (2006), "Wine and globalisation: changes in the international market structure and the position of Italy". British Food Journal, Vol. 108 No. 4, pp. 306-315.

Bisson, L.F., Waterhouse, A.L., Ebeler, S.E., Walker, M.A. and Lapsley, J. T. (2002). “The present and future of the international wine industry", Nature, Vol. 418 No. 6898, p. 696.

Bloch, P.H. (1986), “The product enthusiast: implications for marketing strategy", Journal of Consumer Marketing, Vol. 3 No. 3, pp. 51-62.

Bresciani, S., Ferraris, A., Santoro, G., \& Nilsen, H. R. (2016), “Wine sector: companies' performance and green economy as a means of societal marketing”, Journal of Promotion Management, Vol. 22 No. 2, pp. 251-267.

Bresciani, S., Giacosa, E., Broccardo, L., \& Culasso, F. (2016), “The family variable in the French and Italian wine sector”, EuroMed Journal of Business, Vol. 11 No. 1, pp. 101-118.

Brisoux, J. and Cheron, E. (1990), "Brand categorization and product involvement", Advances in Consumer Research, Vol. 17, pp. 101-109.

Bruwer, J. and Li, E. (2007), "Wine-related lifestyle (WRL) market segmentation: demographic and behavioural factors", Journal of Wine Research, Vol. 18 No. 1, pp. 19-34.

Bruwer, J. and Huang, J. (2012), "Wine product involvement and consumers' BYOB behaviour in the South Australian on-premise market”, Asia Pacific Journal of Marketing and Logistics, Vol. 24 No. 3, pp. 461-481. 
Bruwer, J., Li, E., Lang, S. and Chaumont, S. (2012), “Perspectives on consumers' attitudes to wine's region of origin in a restaurant setting", Journal of Food Service Business Research, Vol. 15 No. 3, pp. 300-318.

Bruwer, J. and Buller, C. (2013), "Product involvement, brand loyalty, and country-of-origin brand preferences of Japanese wine consumers", Journal of Wine Research, Vol. 24 No. 1, pp. 38-58.

Bruwer J., Fong, M. and Saliba A. (2013), "Perceived risk, risk-reduction strategies (RRS) and consumption occasions: Roles in the wine consumer's purchase decision", Asia Pacific Journal of Marketing and Logistics, Vol. 25 No. 3, pp. 369-390.

Bruwer, J., Arias, A.P.P. and Cohen, J. (2017), "Restaurants and the single-serve wine by-the-glass conundrum: risk perception and reduction effects", International Journal of Hospitality Management, Vol. 62, pp. 43-52.

Bruwer, J. and Campusano, P. (2018), "Restaurants and the bring-your-own-bottle of wine paradox: involvement influences, consumption occasions, and risk perception", Journal of Foodservice Business Research, Vol. 21 No. 2, pp. 121-138.

Bruwer, J. and Cohen, J. (2019), "Restaurants and wine by-the-glass consumption: motivational process model of risk perception, involvement and information-related behaviour", International Journal of Hospitality Management, Vol. 77, pp. 270-280.

Campbell, G. and Guibert, N. (2006), "Introduction: Old World strategies against New World competition in a globalising wine industry”, British Food Journal, Vol. 108 No. 4, pp. 233-242.

Campbell, M.C. and Goodstein, R.C. (2001), “The moderating effect of perceived risk on consumers' evaluations of product incongruity: preference for the norm", Journal of Consumer Research, Vol. 28 No. 3, pp. 439-449.

Capasso, A., Gallucci, C., \& Rossi, M. (2015), "Standing the test of time. Does firm performance improve with age? An analysis of the wine industry”, Business History, Vol. 57 No. 7, pp. 10371053.

Carlsen, J. and Boksberger, P. (2015), "Enhancing consumer value in wine tourism", Journal of Hospitality and Tourism Research, Vol. 39 No. 1, pp. 132-144.

Celsi, R. and Olson, J. (1988), "The role of involvement in attention and comprehensive processes", Journal of Consumer Research, Vol. 15 No. 2, pp. 210-224.

Charters, S. and Pettigrew, S. (2007), "The dimensions of wine quality". Food Quality and Preference, Vol. 18 No. 7, pp. 997-1007.

Charters, S. and Ali-Knight, J. (2000), “Wine tourism-A thirst for knowledge?", International Journal of Wine Marketing, Vol. 12 No. 3, pp. 70-80. 
D'Alessandro, S. and Pecotich, A. (2013), "Evaluation of wine by expert and novice consumers in the presence of variations in quality, brand and country of origin cues", Food Quality and Preference, Vol. 28 No. 1, pp. 287-303.

D’Amico, M., Di Vita, G. and Monaco, L. (2016), "Exploring environmental consciousness and consumer preferences for organic wines without sulphites", Journal of Cleaner Production, Vol. 120, pp. 64-71.

Dholakia, U.M. (2001), “A motivational process model of product involvement and consumer risk perception", European Journal of Marketing, Vol. 35 No. 11/12, pp. 1340-1362.

Dodd, T.H., Laverie, D.A., Wilcox, J.F. and Duhan, D.F. (2005), "Differential effects of experience, subjective knowledge, and objective knowledge on sources of information used in consumer wine purchasing”, Journal of Hospitality and Tourism Research, Vol. 29 No. 1, pp. 3-19.

Dodd, T. H., Pinkleton, B. E. and Gustafson, A.W. (1996), "External information sources of product enthusiasts: differences between variety seekers, variety neutrals, and variety avoiders", Psychology \& Marketing, Vol. 1 No. 3, pp. 291-304.

Escobar, C., Kallas, Z. and Gil, J. M. (2018), “Consumers' wine preferences in a changing scenario", British Food Journal, Vol. 120 No. 1, pp. 18-32.

Faison, E.W. (1977), "The neglected variety drive: a useful concept for consumer behaviour", Journal of Consumer Research, Vol. 4 No. 3, pp. 172-175.

Fernandes Ferreira Madureira, T.C. and Simões de Sousa Nunes, F.J. (2013), "Relevant attributes of Portuguese wines: matching regions and consumers' involvement level”, International Journal of Wine Business Research, Vol. 25 No. 1, pp. 75-86.

Forbes (2019). "Record global wine harvest in 2018, stable consumption", available at: https://www.forbes.com/sites/karlsson/2019/04/14/record-global-wine-harvest-in-2018-stableconsumption/\#62bdd67a266b (accessed 15 April 2019).

Frost, D. (2015), “Selling wine: most people don't prefer wine in a bottle, they prefer it in a glass", Restaurantowner.com, available at: www.restaurantowner.com/public/381print.cfm (accessed 15 April 2019).

Galati, A., Crescimanno, M., Tinervia, S. and Fagnani, F. (2017) "Social media as a strategic marketing tool in the Sicilian wine industry: evidence from Facebook", Wine Economics and Policy, Vol. 6 No. 1, pp. 40-47.

Galati, A., Tinervia, S., Tulone, A., Crescimanno, M., \& Rizzo, G. (2018), "Label Style and Color Contribution to Explain Market Price Difference in Italian Red Wines Sold in the Chinese Wine Market”, Journal of international food \& agribusiness marketing, Vol. 30 No. 2, pp. 175-190. 
Galati, A., Schifani, G., Crescimanno, M., \& Migliore, G. (2019), "Natural wine” consumers and interest in label information: An analysis of willingness to pay in a new Italian wine market segment", Journal of Cleaner Production, Vol. 227, pp. 405-413.

Geuens, M. and De Pelsmacker, P. (2017), "Planning and conducting experimental advertising research and questionnaire design”, Journal of Advertising, Vol. 46 No. 1, pp. 83-100.

Giacomarra, M., Galati, A., Crescimanno, M. and Tinervia, S. (2016), "The integration of quality and safety concerns in the wine industry: the role of third-party voluntary certifications", Journal of Cleaner Production, Vol. 112, pp. 267-274.

Gil, I., Berenguer, G. and Ruiz, M.E. (2009), "Wine list engineering: categorization of food and beverage outlets", International Journal of Contemporary Hospitality Management, Vol. 21 No. 1, pp. 69-84.

Gluckman, R.L. (1990), “A consumer approach to branded wines”, European Journal of Marketing, Vol. 24 No. 4, pp. 27-46.

Hayes, A. F. (2017), Introduction to mediation, moderation, and conditional process analysis: $A$ regression-based approach, Guilford Publications, New York NY.

Hansen, K. (2015), "Wines by the glass: sampling, selling, and food pairings are all made easier with single-glass pours", Full Service Restaurant Newsfeed, available at: www.foodnewsfeed.com/fsr/ wine/wines-glass (accessed 15 April 2019).

Hirche, M. and Bruwer, J. (2014), "Buying a product for an anticipated consumption situation: observation of high-and low-involved wine buyers in a retail store", International Journal of Wine Business Research, Vol. 26 No. 4, pp. 295-318.

Hirschman, E.C. (1980), “Innovativeness, novelty seeking, and consumer creativity”, Journal of Consumer Research, Vol. 7 No. 3, pp. 283-295.

Hollebeek, L.D., Jaeger, S.R., Brodie, R.J. and Balemi, A. (2007), "The influence of involvement on purchase intention for new world wine", Food Quality and Preference, Vol. 18 No. 8, pp. 1033-1049. Hussain, M., Cholette, S. and Castaldi, R. (2007), "Determinants of wine consumption of US consumers: an econometric analysis", International Journal of Wine Business Research, Vol. 19 No. 1, pp. 49-62.

Jacob III, D.J. and Neal, J.A. (2011), "Efficacy of preservation methods used for wine by the glass programs in restaurants", Journal of Culinary Science and Technology, Vol. 9 No. 4, pp. 212-227.

Jaeger, S.R., Danaher, P.J. and Brodie, R.J. (2010), "Consumption decisions made in restaurants: the case of wine selection", Food Quality and Preference, Vol. 21 No. 4, pp. 439-442. 
Johnson, T. and Bruwer, J. (2004), “Generic consumer risk-reduction strategies (RRS) in wine-related lifestyle segments of the Australian wine market", International Journal of Wine Marketing, Vol. 16 No. 1, pp. 5-35.

Knox, S. (1998), “Loyalty-based segmentation and the customer development process", European Management Journal, Vol. 16 No. 6, pp. 729-737.

Lacey, S., Bruwer, J. and Li, E. (2009), "The role of perceived risk in wine purchase decisions in restaurants", International Journal of Wine Business Research, Vol. 21 No. 2, pp. 99-117.

Lesschaeve, I. and Bruwer, J. (2010) "The importance of consumer involvement and implications for new product development", In Consumer-driven Innovation in Food and Personal Care Products (pp. 386-423). Woodhead Publishing, Cambridge.

Lockshin, L. and Corsi, A.M. (2012), “Consumer behaviour for wine 2.0: a review since 2003 and future directions", Wine Economics and Policy, Vol. 1 No. 1, pp.2-23.

Lockshin, L.S., Spawton, A.L. and Macintosh, G. (1997), "Using product, brand and purchasing involvement for retail segmentation", Journal of Retailing and Consumer services, Vol. 4 No. 3, pp. 171-183.

Lockshin, L., Wade, J., d'Hauteville, F. and Perrouty, J.P. (2006), “Using simulations from discrete choice experiments to measure consumer sensitivity to brand, region, price, and awards in wine choice", Food Quality and Preference, Vol. 17 No. 3-4, pp. 166-178.

McAlister, L. and Pessemier, E. (1982), "Variety seeking behavior: an interdisciplinary review”, Journal of Consumer Research, Vol. 9 No. 3, pp. 311-322.

Maizza, A. and Rosato, P. (2008, July), "Wine tourism and enhanced value: a comparison between Italian successful destinations", In Proceedings of the 4th International Conference of the Academy of Wine Business Research, pp. 1-14.

Meixner, O. and Knoll, V. (2012), “An expanded model of variety-seeking behaviour in food product choices”, British Food Journal, Vol. 114 No. 11, pp. 1571-1586.

Menon, S. and Kahn, B. E. (1995), "The impact of context on variety seeking in product choices", Journal of Consumer Research, Vol. 22 No. 3, pp. 285-295.

Mintel (2019), Global Food \& Drink Trends 2019, available at https://www.mintel.com/global-foodand-drink-trends

Mitchell, V.W., and Greatorex, M. (1989), "Risk reducing strategies used in the purchase of wine in the UK", European Journal of Marketing, Vol. 23 No. 9, pp. 31-46.

Montaigne, E. and Coelho, A. (2012), "Structure of the producing side of the wine industry: firm typologies, networks of firms and clusters", Wine Economics and Policy, Vol. 1 No. 1, pp. 41-53. 
O’Cass, A. (2000), “An assessment of consumers' product, purchase decision, advertising and consumption involvement in fashion clothing", Journal of Economic Psychology, Vol. 21, pp. 545576.

Ogbeide, O.A., and Bruwer, J. (2013), "Enduring involvement with wine: predictive model and measurement", Journal of Wine Research, Vol. 24 No. 3, pp. 210-226.

Olsen, J.E., Atkin, T., Thach, L. and Cuellar, S.S. (2015), "Variety seeking by wine consumers in the southern states of the US", International Journal of Wine Business Research, Vol. 27 No. 4, pp. 260280.

Orth, U.R. and Bourrain, A. (2005), "Optimum stimulation level theory and the differential impact of olfactory stimuli on consumer exploratory tendencies", Advances in Consumer Research, Vol. 32 No. 1, pp. 613-619.

Palma, D., Cornejo, C., Ortuzar, J. D., Rizzi, L. I. and Casaubon, G. (2014, June), “Tell me why you like to drink wine: drinking motivations for market segmentation", In 7th International Academy of Wine Business Research Conference, Geisenheim (pp. 26-30).

Papatla, P. and Krishnamurthi, L. (1996), "Measuring the dynamic effects of promotions on brand choice", Journal of Marketing Research, Vol. 33 No. 1, pp. 20-35.

Pucci, T., Casprini, E., Nosi, C. and Zanni, L. (2019), "Does social media usage affect online purchasing intention for wine? The moderating role of subjective and objective knowledge", British Food Journal.

Rossi, M., Vrontis, D., \& Thrassou, A. (2014), "Agro business in a changing competitive environment-Campania firms' strategic, marketing and financial choices", World Review of Entrepreneurship, Management and Sustainable Development 5, Vol. 10 No. 2-3, pp. 312-333.

Samoggia, A. (2016), "Wine and health: faraway concepts?”, British Food Journal, Vol. 118 No. 4, pp. 946-960.

Schäufele, I. and Hamm, U. (2017), “Consumers' perceptions, preferences and willingness-to-pay for wine with sustainability characteristics: a review", Journal of Cleaner Production, Vol. 147, pp. 379394.

Schiffman, L.G., O’Cass, A., Paladino, A., D’Alessandro, S. and Bednall, D. (2011), Consumer Behaviour, 5th ed. Pearson Education, Frenchs Forest, NSW, Australia, pp. 1-662.

Sekaran, U. (1983), "Methodological and theoretical issues and advancements in cross-cultural research", Journal of International Business Studies, Vol. 14 No. 2, pp. 61-73.

Shepherd, D.A., Douglas, E.J. and Shanley, M. (2000), "New venture survival: ignorance, external shocks, and risk reduction strategies", Journal of Business Venturing, Vol. 15 No. 5-6, pp. 393-410. 
Sweeney, J. C. and Soutar, G. N. (2001), “Consumer perceived value: the development of a multiple item scale", Journal of Retailing, Vol. 77 No. 2, pp. 203-220.

Terrier, L. and Jaquinet, A. L. (2016), "Food-wine pairing suggestions as a risk reduction strategy: reducing risk and increasing wine by the glass sales in the context of a Swiss restaurant", Psychological Reports, Vol. 119 No. 1, pp. 174-180.

Thanh, T.V. and Kirova, V. (2018), "Wine tourism experience: a netnography study", Journal of Business Research, Vol. 83, pp. 30-37.

Tiu Wright, L., Nancarrow, C. and Kwok, P.M. (2001), "Food taste preferences and cultural influences on consumption", British Food Journal, Vol. 103 No. 5, pp. 348-357.

Unione Italiana Vini (2019), available at https://www.unioneitalianavini.it/fuori-casa-il-vino-albicchiere-piace-di-piu/

Wansink, B., Cordua, G., Blair, E., Payne, C. and Geiger, S. (2006), "Wine promotions in restaurants: do beverage sales contribute or cannibalize?" Cornell Hotel and Restaurant Administration Quarterly, Vol. 47 No. 4, pp. 327-336.

World Health Organization (WHO) (2014), "Global Status Report on Alcohol and Health", Luxembourg.

Yim, C.K. and Kannan, P.K. (1999), "Consumer behavioral loyalty”, Journal of Business Research, Vol. 44 No. 2, pp. 75-92.

Yoon, E. and Stacy, M. (2015), The billion-dollar opportunity in single-serve food. Harvard Business Review, available online at: https://hbr. org/2015/10/the-billion-dollar-opportunity-in-single-servefood (accessed 15 April 2019).

Zaichkowsky, J.L. (1985), "Measuring the involvement construct", Journal of Consumer Research, Vol. 12 No. 3, pp. 341-352. 